\title{
Ações estratégicas e visões dos atores do cluster de turismo da cidade de São Paulo
}

\section{Strategic actions and visions of the stakeholders of the São Paulo city's tourism cluster}

\section{Acciones estratégicas y visiones de los actores del cluster de turismo de la ciudad de San Pablo}

\author{
Edegar Luis Tomazzoni ${ }^{1}$ \\ Juliana Soares Costa ${ }^{2}$
}

\begin{abstract}
Resumo: O maior destino de turístico de negócios da América Latina define o tempo de permanência dos turistas, implicando a sazonalidade do turismo da cidade de São Paulo. O objetivo do artigo é analisar as visões dos gestores das organizações representativas (atores do cluster do turismo) sobre o aumento do fluxo e do tempo de permanência dos turistas na cidade de São Paulo. A pesquisa é de natureza descritiva e exploratória, e o método de campo consistiu de entrevistas com os gestores da São Paulo Turismo (SPTuris), do São Paulo Convention \& Visitors Bureau (SPCVB), da Secretaria Municipal de Cultura e do Fórum de Operadores Hoteleiros do Brasil (FOHB) e de aplicação de questionário a gestores de 25 hotéis. Os resultados mostram que, apesar da grande concentração de empresas e de organizações, que constituem o cluster de turismo, poderia haver mais cooperação entre os atores para reduzir a sazonalidade e para aumentar o fluxo de turistas e a ocupação hoteleira da cidade de São Paulo, aos finais de semana, nos feriados e nos períodos de férias.
\end{abstract}

Palavras-Chave: Turismo. Sazonalidade. Cooperação. Cluster. Cidade de São Paulo.

Abstract: The main destination for tourism business in Latin America sets the time of stay of tourists, implying the seasonality of tourism in the city of Sao Paulo. The aim of this paper is to analyze the managers' views of representative organizations (actors in the cluster of tourism) on increasing the flow and the tima of stay of tourists in the city of Sao Paulo. The research is of descriptive and exploratory nature, and the field method consisted of interviews with the managers of São Paulo Turismo (SPTuris), São Paulo Convention \& Visitors Bureau (SPCVB), the Municipal Department of Culture and Brazilian Operators Forum Hoteliers (BOFH) and application of questioners to 25 hotel managers. The results show that despite the large concentration of businesses and organizations that constitute the tourism cluster, there could be more cooperation between the actors to reduce the seasonality of tourism and increase the flow of tourists and the hotels occupancy of the city of São Paulo, in the weekends and during holiday periods.

Keywords: Tourism. Seasonality. Cooperation. Cluster. City of São Paulo.

${ }^{1}$ Universidade de São Paulo (USP). E-mail: eltomazzoni@usp.br

2 Universidade de São Paulo (USP). E-mail: juliana.soares.costa@usp.br 
Resumen: El principal destino turístico de negocios en América Latina define la duración de la estancia de los turistas, lo que implica la estacionalidad del turismo en la ciudad de San Pablo. El objetivo de este trabajo es analizar los puntos de vista de los directivos de las organizaciones representativas (los actores del cluster de turismo) en el aumento del flujo y de la duración de la estancia de los turistas en la ciudad de San Pablo. La investigación es descriptiva y exploratoria, y el método de campo consistió en entrevistas con los gerentes de la São Paulo Turismo (SPTuris), del São Paulo Convention \& Visitors Bureau (SPCVB), del Departamento Municipal de Cultura y del Foro de Operadores Hoteleros de Brasil (FOHB) e aplicación de cuestionarios a 25 administradores de hoteles. Los resultados muestran que a pesar de la gran concentración de empresas y organizaciones que constituyen el cluster de turismo, podría haber más cooperación entre los agentes para reducir la estacionalidad y aumentar el flujo de turistas y la ocupación hotelera de la ciudad de San Pablo, el los fines de semana, días festivos y em los periodos vacacionales.

Palabras clave: Turismo. Estacionalidad. Cooperación. Cluster. Ciudad de San Pablo.

\section{INTRODUÇÃO}

O calendário São Paulo é a maior cidade do Brasil tanto em população quanto em Produto Interno Bruto (PIB). (IBGE, 2012). É sede de grandes bancos nacionais e internacionais, registra expressivo número de eventos (congressos e feiras) e mundialmente conhecida como uma das melhores cidades para se investir e para realizar negócios, de acordo com o São Paulo Convention \& Visitors Bureau (SPCVB, 2012) e a São Paulo Turismo (SPTuris, 2012), a megalópole tem a maior rede de serviços de turismo e lazer do país. São 410 hotéis, com 42 mil leitos, 12,5 mil restaurantes e 160 teatros. A cidade recebeu 11,7 milhões de visitantes em 2010, entre os que vêm a negócios e a lazer e que se hospedam na rede hoteleira. Destes, 10,1 milhões eram turistas nacionais e 1,6 milhão eram estrangeiros. O crescimento foi de 3,54\% em relação a 2009. (SPCVB, 2012; SPTuris, 2012).

A maior estabilidade econômica do país contribuiu para melhorar a imagem de São Paulo no exterior. De acordo com o São Paulo Convention \& Visitors Bureau (SPCVB, 2012) e a São Paulo Turismo (SPTuris, 2012), a cidade está em quarto lugar no ranking das vinte e duas cidades que mais receberam investimentos estrangeiros em 2011, atrás de Londres, Xangai e Hong Kong. Recebeu investimentos de 8,4 bilhões de dólares em 2011 (em 2006, foram 600 milhões). Passou do vigésimo para o nono principal destino de profissionais estrangeiros que se estabelecem no Brasil.

Com base em dados de entidades da hotelaria local, como o do Fórum de Operadores Hoteleiros do Brasil (FOHB), do SPCV e da SPTuris, 20\% do público dos espetáculos musicais vêm de fora da cidade. As produções atraem de 120 mil a 200 mil espectadores por temporada. Os pacotes de fins de semana culturais, com restaurantes, compras e museus, são vendidos pelas agências a mil reais por pessoa, e o que realmente atrai as pessoas são os espetáculos teatrais. Em razão de estar se tornando destino de lazer e cultura, além de cidade de negócios, a taxa de ocupação dos hotéis aumentou de $30 \%$ para $60 \%$, nos últimos onze anos, e os espetáculos musicais têm contribuído significativamente para esse crescimento. (FOHB, 2012; SPCVB, 2012; SPTuris, 2012). 
Apesar dos diferenciais competitivos como centro internacional de negócios e como destino turístico de lazer e cultura, a demanda hoteleira da cidade de São Paulo ainda apresenta redução em determinados períodos, principalmente, aos finais de semana, nos feriados prolongados e nas férias escolares e de verão. Tais aspectos reforçam seu perfil de turismo de negócios. A maioria dos turistas permanece na cidade durante os dias de trabalho e, aos finais da semana, retornam para suas cidades de origem. A demanda turística nos períodos de férias é significativamente menor do que a de outros destinos do país, configurando-se a sazonalidade do turismo paulistano.

As várias organizações públicas e privadas de turismo - São Paulo Turismo (SPturis); São Paulo Convention \& Visitors Bureau (SPCVB); Secretaria Municipal da Cultura; Associações e Sindicatos da Hotelaria, como o do Fórum de Operadores Hoteleiros do Brasil (FOHB), bem como centenas de empresas de diversos segmentos turísticos - ainda não teriam consolidado parcerias em sistema de rede de cooperação abrangente, no contexto do cluster de turismo, para aumentar a fluxo turístico e a ocupação hoteleira aos finais de semana, nos feriados prolongados e nos períodos de férias. Nesse sentido, faltaria maior envolvimento das empresas dos segmentos turísticos contemplados e mais investimentos em divulgação dos atrativos.

Este trabalho estuda a atuação e a articulação dos principais atores, ou direções e gestores de organizações representativas do turismo e da hotelaria da cidade de São Paulo. A análise fundamenta-se no referencial teórico de cluster, que no Brasil é também conhecido como arranjo produtivo local (APL). A visão da realidade do turismo, com base na teoria de clusters, possibilita identificar funções, responsabilidades, desafios e oportunidades das organizações representativas, ou dos atores do setor turístico.

Em razão disso, o objetivo geral deste estudo é analisar as visões dos gestores das organizações representativas ou atores do turismo sobre o fluxo e o tempo de permanência dos turistas, nos finais de semana e nos feriados e nos períodos de férias e sobre a redução da sazonalidade do turismo na cidade de São Paulo. A fim de cumprir o objetivo geral, o objetivo específico é verificar as relações de cooperação entre as organizações representativas ou atores do setor público e da iniciativa privada (especialmente a hotelaria), que constituem o cluster de turismo da cidade de São Paulo.

$\mathrm{O}$ artigo estrutura-se em cinco seções, incluindo esta introdução como a primeira. A segunda seção apresenta revisão conceitual de cluster de turismo. Na terceira seção, descreve-se o método de pesquisa. Na quarta seção, apresentam-se dados e aspectos da configuração do turismo de negócios e de lazer na cidade de São Paulo. Na quinta seção, descrevem-se as visões dos atores do cluster de turismo da cidade de São Paulo e discutem-se os resultados da pesquisa. As considerações finais complementam as análises.

\section{CLUSTER DE TURISMO}


Com o aprofundamento da análise das aglomerações ou cadeias produtivas, Schumpeter (1985), foi um dos pioneiros a identificar os clusters como agrupamentos industriais estratégicos para o desenvolvimento econômico, inspirado na metáfora do enxame de empresários. Porter (1999) explica que clusters são concentrações geográficas de empresas que cooperam e competem entre si.

O cluster proporciona vantagens estratégicas como: abrangência de fornecedores, dos canais de distribuição e de acessos aos clientes; presença de instituições governamentais e de ensino; fomento à produtividade; estímulo à inovação e aos novos negócios; acesso a empregos, a informações e a conhecimentos; atração de atividades correlatas; incentivo à qualidade; poder de influência; valorização de localização e do ambiente circundante. (PORTER, 1999).

As diversas vantagens do cluster destacadas por Porter são fundamentais para o planejamento e a gestão estratégica das aglomerações territoriais de empresas e de organizações correlatas. Ainda que a concentração geográfica seja decorrente da iniciativa de empreendedores inovadores, de acordo com a elucidação de Schumpeter, o conhecimento e as vantagens do cluster podem ser potencializados pela cooperação entre os atores organizacionais, visando ao objetivo comum de conquistar retornos coletivos.

Muitas empresas e organizações dos segmentos de turismo não se relacionam entre si com o propósito de gerar resultados coletivos, por meio da governança do cluster do turismo. A cooperação proporcionaria eficiência coletiva, conforme definição de Amato Neto (2008). O cluster tem maior capacidade de sobreviver à instabilidade do ambiente do que as empresas isoladas, em virtude da ação estratégica em conjunto e de sua alta capacidade de autoestruturação, intrínseca à própria forma organizacional em rede. Entende-se, portanto, que os resultados do cluster são gerados não pelas concentrações setorial e geográfica, mas pelo processo de relações entre as empresas.

Nesse sentido, é importante que as relações interorganizacionais, ou sistêmicas, do cluster sejam coordenadas, que haja convergência de visões, de interesses e de ações estratégicas dos atores. A coordenação sistêmica, implícita à articulação estratégica da rede de intercâmbios e de cooperação do cluster, é a governança, cujo sentido é a coordenação da convergência de interesses e a gestão participativa para realização de objetivos comuns, visando ao desenvolvimento socioeconômico. A governança envolve as atividades econômicas e sociais, legitimamente representadas pelas organizações públicas e privadas.

Para Santos (1997, p. 342), a governança constitui-se em

padrões de articulação e de cooperação entre atores sociais e políticos e arranjos institucionais, que coordenam e regulam transações dentro e através das fronteiras do sistema econômico. Incluem-se não apenas os mecanismos tradicionais de agregação e articulação de interesses, tais como os partidos políticos e grupos de pressão, como também redes sociais informais (de fornecedores, famílias, gerentes), hierarquias e associações diversas. 
Entre as diversas vantagens da governança do cluster, destaca-se a competividade. De acordo com Cassiolato e Szapiro (2003a, p. 35), "é amplamente aceito que as fontes locais da competitividade são importantes, tanto para o crescimento das firmas quanto para o aumento da sua capacidade inovativa". Os autores argumentam, com base nas experiências japonesa e da Terceira Itália, que "a cooperação entre agentes ao longo da cadeia produtiva é cada vez mais destacada como elemento fundamental da competitividade". (IBIDEM).

Os exemplos das experiências de sucesso no exterior validam as discussões teóricas dos autores e são importantes para motivar ações estratégicas similares no Brasil. A competitividade do agrupamento depende da força dos elos que unem as empresas, proporcionando aumento da produtividade e condições favoráveis ao surgimento de novas empresas. Os setores empresariais e os produtos complementam-se entre si.

Retomando as abordagens dos autores clássicos, além dos aspectos-chave do cluster, como a cooperação entre organizações públicas e privadas e a capacidade de financiamento. $\mathrm{O}$ cluster abrange o conceito de rede, como estratégia pela qual as organizações reúnem e trocam recursos e desenvolvem ideias e competências, formando um pool de conhecimentos necessários às inovações. (FORTES, 2010).

A fundamentação conceitual de cluster aplica-se especialmente ao turismo, contemplando suas múltiplas dimensões e segmentos. Nesse sentido, o embasamento do arcabouço teórico da área é o conceito de cluster de turismo, definido por Beni (2001, p. 7) como: "conjunto de atrativos com destacado diferencial, concentrado num espaço geográfico contínuo ou descontínuo, dotado de equipamentos, instalações e serviços de qualidade, com eficiência coletiva, coesão social e política, cultura de articulação associativa com excelência gerencial, em redes de empresas que geram vantagens estratégicas comparativas e competitivas".

O autor enfatiza que são necessárias ações de política estratégica na implantação de clusters de turismo, por meio de postura ativa, visão compartilhada do futuro, cidadania, iniciativa, cooperação. Como estratégias de cooperação, Beni (2011) destaca criação de associações representativas e fóruns de discussão para maior influência, poder de negociação para maior competitividade no mercado.

Silva (2004) classifica cluster de turismo com base em duas visões: uma de natureza geral, identificada pelas zonas e polos turísticos regionais, e outra, de natureza específica, vinculando municípios e localidades, que integram as zonas turísticas, bem como os diferentes segmentos turísticos regionais competitivos.

No cluster de turismo, as empresas, as organizações e as instituições estabelecem interações entre si no contexto da cadeia produtiva do turismo, envolvendo o intercâmbio de fatores e competências na produção da oferta dos produtos turísticos.

Para Cunha e Cunha (2006, p. 61), clusters, também definidos como redes de cooperação, "permitem explorar de maneira eficaz as eficiências coletivas e/ou desenvolver as economias externas nas relações sociais de produção". No caso do cluster de turismo: 
existe um âmbito geográfico local, medido em função de conexões reais; conforme relações comerciais, entendidas como a distância máxima que permite a um fornecedor servir adequadamente aos seus clientes e desenvolver outras atividades complementares, bem como muitos outros aspectos a exemplo da promoção, das escolas de formação turística, etc.; contém infraestruturas suficientes para toda a área; dispõe de uma estratégia própria muito diferenciada, com características de oferta ou de demanda muito distintas em relação ao resto do território. (Cunha e Cunha, 2006, p. 61).

A figura 1, a seguir, é uma representação da relação dos atores e dos elementos do cluster de turismo:

Figura 1 - Cluster de Turismo

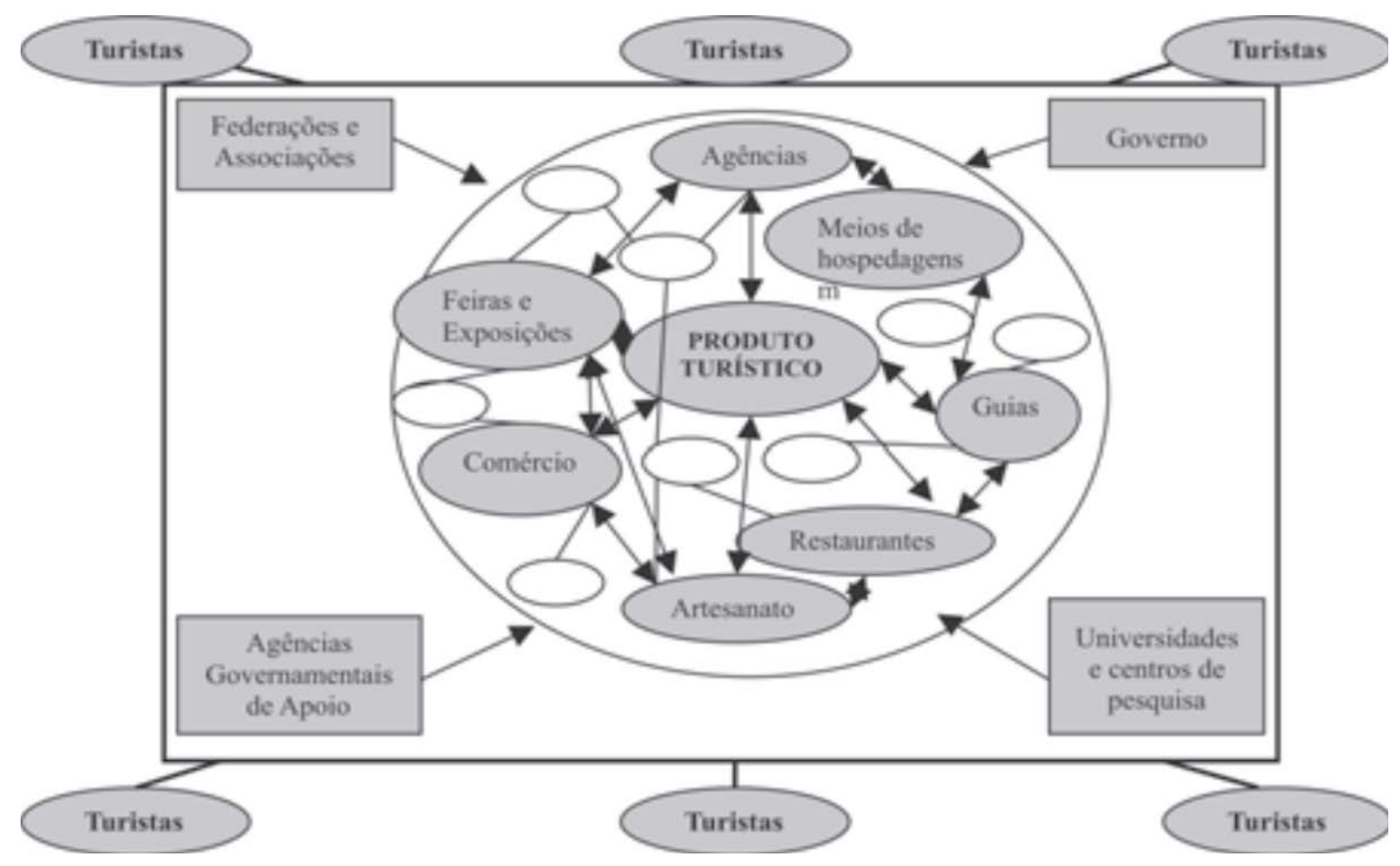

Fonte: Cunha e Cunha (2006)

A figura 1 mostra que Cunha e Cunha (2006) identificam densas relações de interação, de cooperação e de competição dos agentes de um cluster de turismo - as firmas (fornecedores, clientes e competidores) e as instituições públicas e privadas e representantes da sociedade civil. As relações entre os atores organizacionais e institucionais identificadas por Cunha e Cunha (2006) são fundamentais para as estratégias e políticas macroeconômicas de desenvolvimento sustentável do turismo.

Thomazi (2006) argumenta que os clusters podem diferenciar-se em tamanho, amplitude e estágio de desenvolvimento, o que determinará a natureza de sua apresentação. Essas características torna cada cluster diferente dos demais e faz com que nunca haja um cluster igual ao outro, podendo englobar desde empresas de pequeno porte até empresas de grande porte. Orlando, nos Estados Unidos, é destacado pela autora, como exemplo de cluster de turismo: 
zona geográfica que concentra um dos centros de entretenimento mais desenvolvidos e visitados do mundo, [...] um conjunto de hotéis, restaurantes, centro de diversão, infraestrutura e serviços especializados de transporte e segurança para diversos segmentos de visitantes, permitindo que os principais distribuidores se especializem na venda desse cluster, ampliando a produtividade dele. (Thomazi, 2006, p. 48).

Para Thomazi (2006), a característica marcante desse cluster é renovar suas atrações por períodos anuais, seja parcialmente ou totalmente. Compõe-se de atrações como Universal Studios, Sea World, Six Flags Water World e Busch Gardens, que são concorrentes entre si, o que estimula a competitividade e torna necessária a inovação contínua.

Mesmo que não sejam tão avançados e competitivos quanto os exemplos citados por Cunha e Cunha (2006), são diversos os aglomerados de turismo no cenário brasileiro, em que aparecem setores que, embora estejam ligados a diferentes áreas, relacionam-se entre si e apresentam potencialidades para o desenvolvimento do cluster.

A fim de tornar mais didática a abordagem de cluster, tem-se difundido no Brasil o conceito de arranjo produtivo local (APL). Albagli e Britto (2003) explicam que APL é aglomeração territorial com foco em um conjunto específico de atividades econômicas, com vínculos e interdependências.

Essa visão da diversidade de aglomerados aplica-se à contextualização do arranjo produtivo local na segmentação turística. Como segmentos do mercado de turismo, Ansarah (2005) destaca desde o turismo científico, até o turismo espacial. A autora, entretanto, questiona se o mercado está preparado para atender e para satisfazer uma demanda tão diversificada. 0 turismo abrange públicos com interesses específicos, e os profissionais que atuam nos seus diversos segmentos devem conhecer os princípios de marketing turístico.

O arranjo produtivo é o elemento base para a configuração de um cluster. Aglomeração, afinidade e articulação são as três características fundamentais para a formação de um arranjo produtivo local. (Lohmann e Panosso Netto, 2008). Além da preexistência do arranjo produtivo local pela sua configuração territorial de aglomeração, as características de afinidade e de articulação fundamentam-se no interesse dos membros das empresas dos segmentos do turismo. As dificuldades dos intercâmbios para a competividade do cluster vão desde a superação do individualismo, até a resistência à cooperação para vencer desafios inerentes aos destinos turísticos, como a sazonalidade.

As causas da sazonalidade, definida como oscilações de fluxos e de concentrações de demandas em períodos diversos, variam de acordo com as características dos destinos turísticos, bem como em razão de fatores controláveis ou incontroláveis. O contexto climático, as atividades econômicas da conjuntura industrial e comercial, as férias profissionais e escolares determinam tanto a configuração da sua oferta quanto da sua demanda turísticas.

As vantagens e as desvantagens da sazonalidade são temas de importantes discussões, de pesquisas e de análises. Nesse sentido, estudos acadêmicos contribuem para a redução de seus impactos negativos, por meio de conhecimentos sobre criação e inovação de produtos, atrativos e serviços, com base em estratégias eficazes de planejamento, de marketing e de gestão 
organizacional do turismo. (Lage e Milone, 2001; Cooper, C. at al, 2001; Mota, 2001; Pearce, 2003).

A maior articulação e cooperação entre os atores do cluster do turismo e da hotelaria, para fortalecimento da gestão integrada dos atrativos da cidade de São Paulo, proporcionariam aumento da demanda, do fluxo e do tempo de permanência dos turistas na cidade, reduzindo eventuais períodos de sazonalidade. Haveria também melhorar qualificação dos serviços, intercâmbios de conhecimentos e de experiências, redução de custos e aumentos dos retornos dos investimentos.

\section{MÉTODO}

O método da pesquisa de natureza qualitativa e exploratória e descritiva, além da revisão teórica, consistiu-se em coleta de campo, realizada por meio de busca de dados nas organizações do setor, de entrevistas com seus diretores e de aplicação de questionários a gestores de hotéis.

As entrevistas foram realizadas com as direções da São Paulo Turismo (SPTuris), do São Paulo Convention \& Visitors Bureau (SPCVB), da Secretaria Municipal da Cultura e do Fórum de Operadores Hoteleiros do Brasil (FOHB). As direções da Associação Brasileira de Gastronomia, Hospedagem e Turismo (ABRESI) e a Associação Brasileira da Indústria de Hotéis (ABIH) mesmo com insistentes solicitações, não se se dispuseram a participar da pesquisa.

Para conhecer a visão dos gestores hoteleiros, foi definido um universo de 100 hotéis, localizados na Zona do Centro e na Zona Sul, próximos à contração financeira, econômica e cultural da cidade, na região da Avenida Paulista. Gestores de 25 hotéis responderam ao questionário. Quanto às categorias, cinco são de luxo ou superluxo (cinco estrelas), dez de categoria superior (quatro estrelas), seis são de categoria turística (três estrelas) conforme a classificação da ABIH, e quatro são de categoria econômica (duas estrelas).

A fim de tornar a aplicação dos instrumentos de pesquisa de campo (coleta qualitativa e quantitativa de dados) didática e produtiva, definiram-se as temáticas pontualmente abordadas nas entrevistas e nos questionários com base nas variáveis:

1) Sazonalidade: indicadores de fluxo e taxas de ocupação; 2) Ações estratégicas de inovação: novas realizações de eventos e de campanhas nos períodos de baixa temporada; resultados das ações para aumento da permanência dos turistas; fluxo dos turistas aos atrativos culturais; 3) Segmentação da oferta turística: segmentos mais procurados pelos turistas de negócios na cidade de São Paulo (gastronomia, eventos artísticos, compras, esportes); 4) Cooperação, intercâmbio e governança: participação das organizações setoriais na promoção do turismo cultural da cidade de São Paulo em sistema de redes de cooperação; participação dos hotéis e das redes hoteleiras nos projetos e nas campanhas turísticas, com base nos principais segmentos; 5) Potencialidades, desafios e competitividade: qualidade geral dos serviços da hotelaria; principais problemas e desafios do turismo da cidade de São Paulo. 
A pesquisa de campo foi realizada no período de 15 de junho a 1 de outubro de 2012. As entrevistas com as direções das entidades continham dez questões abertas, e os questionários com os gestores dos hotéis continham dez questões fechadas e quatro questões abertas.

\section{TURISMO DE NEGÓCIOS E DE LAZER NA CIDADE DE SÃO PAULO}

Mesmo com a diversidade gastronômica e com a riqueza cultural, o segmento de turismo de lazer representou apenas 9,6\% do total do fluxo turístico, entre os meses de janeiro a junho de 2010, de acordo com a pesquisa realizada pelo Observatório do Turismo da Cidade de São Paulo e SPTuris .

Em razão do crescimento do turismo de negócios e de eventos profissionais, a hotelaria da cidade adaptou-se para atender aos turistas desses segmentos, elaborando estratégias para atraílos e para satisfazer suas necessidades. Esse crescimento gera fluxos sazonais, haja vista que a demanda turística da cidade de São Paulo, em sua maioria, é de turistas que viajam a negócios durante dos dias de semana.

No primeiro semestre de 2008, com base na pesquisa online realizada pelo Fórum de Operadores Hoteleiros do Brasil (FOHB) e publicada pela SPTuris em seu Observatório, a principal motivação para os turistas que se hospedaram na cidade de São Paulo foi negócios no segmento de finanças e serviços, representando $32,8 \%$.

No primeiro semestre de 2009, conforme dados da SPTuris, no Boletim Semestral do Observatório do Turismo, 61,6\% do total de turistas visitaram a cidade motivados por negócios, e 18,1\% motivados por eventos. Em 2010, foram de 56,1\% a negócios, e 20,9\% a eventos. (SPTURIS, 2010).

Esse desempenho é em razão de São Paulo ser líder em eventos técnicos, comerciais, industriais, científicos e profissionais na América Latina, com cerca de 90 mil realizações por ano. Detém $75 \%$ do mercado brasileiro de grandes feiras, com 20 centros de feiras e convenções de grande porte, entre eles o maior da América Latina, o Parque Anhembi. (SPTURIS, 2010).

$\mathrm{Na}$ análise do perfil dos hóspedes em meios de hospedagem paulistanos, do segundo semestre de 2011, o Observatório do Turismo da SPTuris verificou que os maiores números de check in e de check out por hóspedes brasileiros no segundo semestre do ano foram em dias úteis. Além disso, o estudo identifica o primeiro e o último dia da semana de estada dos hóspedes na cidade. A grande maioria dos turistas não permanece em São Paulo aos finais de semana. Mais de $70 \%$ chegam entre as segundas-feiras e as quartas-feiras, enquanto mais de $80 \%$ partem da cidade até as sextas-feiras. A taxa média de ocupação dos hotéis durante os dias úteis, segundas-feiras a sextas-feiras, é de $82 \%$, e nos finais de semana é de $58 \%$. A ocupação nos finais de semana, portanto, é aproximandamente $40 \%$ menor que a ocupação durante os dias de semana.

Com base nos dados de estudos de março de 2012 sobre o desempenho dos meios de hospedagem paulistanos, disponíveis no Observatório de Turismo da Cidade de São Paulo, a hotelaria local apresentou as seguintes taxas de ocupação nos últimos sete anos: 
Tabela 1 - Taxas Médias de Ocupação da Hotelaria DESEMPENHO MENSAL ENTRE 2005 A 2012 (\%)

\begin{tabular}{c|c|c|c|c|c|c|c|c|c|c|c|c|}
\hline & JAN & FEV & MAR & ABR & MAI & JUN & JUL & AGO & SET & OUT & NOV & DEZ \\
\hline $\mathbf{2 0 0 5}$ & 45,0 & 46,8 & 57,9 & 59,3 & 58,0 & 62,7 & 62,1 & 64,3 & 68,5 & 63,4 & 64,3 & 52,1 \\
\hline $\mathbf{2 0 0 6}$ & 56,3 & 58,9 & 63,7 & 63,4 & 64,6 & 62,7 & 67,7 & 70,1 & 65,0 & 78,2 & 65,5 & 60,8 \\
\hline $\mathbf{2 0 0 7}$ & 56,4 & 62,0 & 69,8 & 67,4 & 69,3 & 67,6 & 66,5 & 69,4 & 66,9 & 75,2 & 67,6 & 65,9 \\
\hline $\mathbf{2 0 0 8}$ & 53,8 & 59,3 & 69,1 & 70,3 & 70,0 & 74,8 & 68,2 & 71,6 & 76,6 & 71,0 & 72,0 & 51,2 \\
\hline $\mathbf{2 0 0 9}$ & 51,6 & 49,0 & 66,4 & 54,9 & 62,4 & 66,0 & 62,7 & 65,8 & 64,6 & 70,3 & 70,3 & 52,7 \\
\hline $\mathbf{2 0 2 0}$ & 54,3 & 57,8 & 74,1 & 70,1 & 73,3 & 68,0 & 67,7 & 75,1 & 72,9 & 71,9 & 79,6 & 57,7 \\
\hline $\mathbf{2 0 1 1}$ & 56,8 & 69,1 & 67,6 & 72,9 & 74,7 & 75,0 & 66,1 & 75,4 & 70,6 & 72,4 & 75,6 & 55,5 \\
\hline MÉDIA & 53,4 & 57,5 & 66,9 & 65,5 & 67,5 & 68,1 & 65,9 & 70,2 & 69,3 & 71,8 & 70,7 & 56,5 \\
\hline
\end{tabular}

A representação gráfica dos dados torna mais claras as diferenças das taxas de ocupação durante os anos e a configuração da sazonalidade do turismo.

Figura 1 - Gráfico das Taxas Médias Mensais de Ocupação da Hotelaria (2005 - 2011)

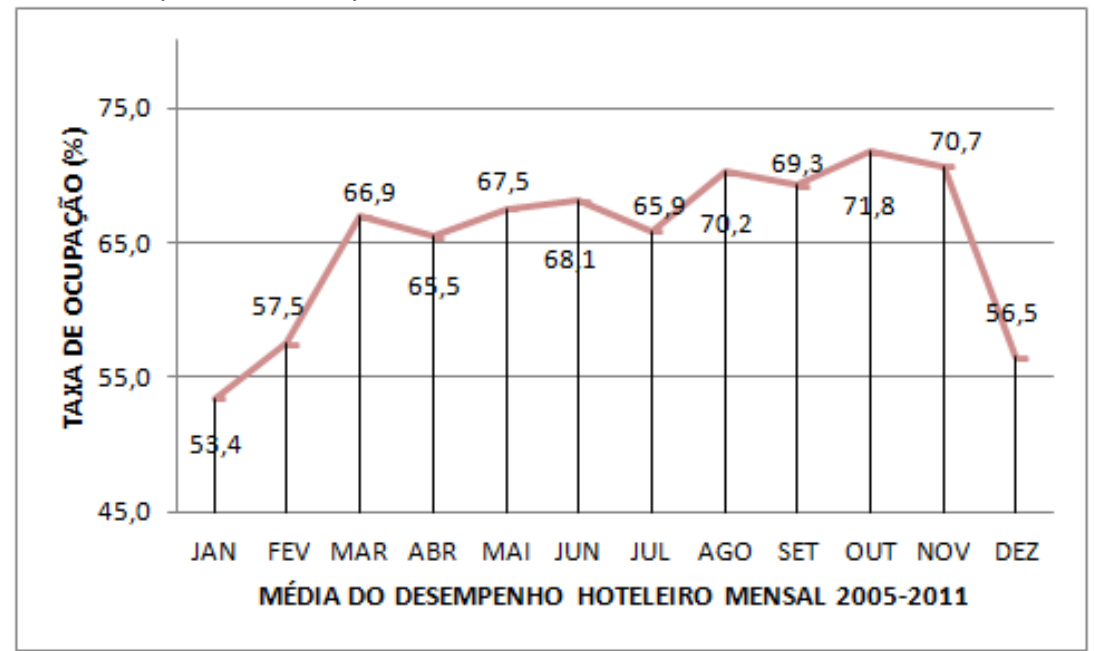

Fonte: Observatório do Turismo da Cidade de São Paulo, SPturis (2012)

Os meses em que os hotéis apresentaram menor ocupação foram fevereiro, dezembro e janeiro, períodos de férias, configurando-se, portanto, o período de baixa estação do turismo. Apesar do aumento, de acordo com o SPCVB (2012) e a SPTuris (2012), nos últimos 11 anos, da ocupação hoteleira de $30 \%$ para $60 \%$, o destino cidade de São Paulo ainda se destaca por receber o turista corporativo, com objetivo de participar de feiras, congressos e eventos profissionais e de realizar negócios.

\subsection{A visão dos atores do cluster de turismo da cidade de São Paulo}

Os sujeitos da pesquisa de campo deste estudo foram as direções da São Paulo Turismo (SPturis); do São Paulo Convention \& Visitors Bureau (SPCVB); da Secretaria Municipal da Cultura; do Fórum de Operadores Hoteleiros do Brasil (FOHB) e os gestores de 25 hotéis localizados nas zonas Centro e Sul da cidade. 
A São Paulo Turismo (SPTuris) é sociedade anônima, com capital aberto e tem como sóciomajoritária a Prefeitura da São Paulo. A empresa atua para promover a cidade como centro dos negócios da América Latina e para torná-la referência também em entretenimento, lazer e conhecimento.

O São Paulo Convention \& Visitors Bureau (SPCVB) é entidade sem fins lucrativos, que atua na captação de negócios, por meio da atividade turística, com o objetivo de aumentar a demanda e a permanência dos turistas na cidade de São Paulo. Congrega mais de 600 associados que representam diversos segmentos do turismo paulistano. A fundação é mantida por pagamento de taxa mensal pelos associados.

A Secretaria Municipal de Cultura é órgão da Prefeitura da cidade de São Paulo. Formula políticas públicas, cria, apoia projetos e desenvolvam atividades na área em que atua.

O Fórum de Operadores Hoteleiros do Brasil (FOHB) é entidade representativa da hotelaria nacional. Composto por 24 redes nacionais e internacionais que atuam no país, tem como objetivos desenvolver o setor hoteleiro, fortalecer o relacionamento dos associados com outros setores, desenvolver o mercado turístico-hoteleiro, por meio de projetos de capacitação e qualificação profissional, e promover difusão de conhecimento entre seus associados.

Quanto às visões, em relação à promoção do turismo da cidade de São Paulo, a direção da SPTuris considera que a participação dos hotéis é limitada, e a direção do SPCVB considera que os hotéis participam ativamente. Em relação ao percentual de participação dos hotéis em campanhas de promoção, para a direção da SPTuris, é de $20 \%$, e para a direção do SPCVB é entre $60 \%$ e $80 \%$.

Para a direção da SPTuris, as redes hoteleiras que mais participam de campanhas de promoção são: Accor, Blue Tree, Tivoli, Renaissance, Pergamon e L'Hotel. De acordo com a direção do SPCVB, as redes que mais participam são: Accor, Meliá, Atlântica e Blue Tree.

De acordo com as direções das duas organizações, não é possível informar o aumento percentual na demanda turística gerado pelas campanhas das entidades, pois não há monitoramento desse crescimento. Quanto aos segmentos que os turistas de negócios mais procuram na cidade, as duas direções destacaram gastronomia, cultura (teatros, shows) e compras.

Solicitou-se a opinião das direções das duas entidades sobre o Programa Destinos Indutores, do Ministério do Turismo, considerando os resultados e benefícios da iniciativa para a cidade de São Paulo. Para o SPCVB, todo programa de promoção da cidade contribui para aumentar a demanda turística. Para a SPTuris, o Programa é importante sob o ponto de vista de planejamento estratégico, porém, é preciso que ele tenha continuidade, e o mais importante são os indicadores criados pelo estudo de competitividade, mas que, tendo em vista as mudanças no Ministério do Turismo, não tiveram continuidade.

As direções das duas entidades responderam que os gestores dos hotéis sugerem alternativas plausíveis e viáveis para aumentar a demanda turística aos finais de semana, nos feriados e nas férias. Acrescentam que é viável a realização de eventos ligados a negócios nos 
períodos de baixa temporada paulistana e que é importante a ampliação do calendário de eventos da cidade.

Além disso, é preciso desenvolver promoções pontuais junto aos hotéis para estimular agendamento de eventos em finais de semana e em períodos de baixa temporada (como férias escolares). Para a direção da SPTuris, entretanto, a cidade de São Paulo não apresenta acentuada oscilação entre os períodos de alta e de baixa ocupação.

A "São Paulo Best Week", campanha que estimula o "consumo" da cidade de São Paulo durante feriados prolongados, por meio de ofertas realizadas pelos estabelecimentos, é citada como exemplo pelo SPCVB e pela SPTuris.

De acordo com as direções das duas entidades, existem parcerias com organizações da cultura e entidades associativas da hotelaria para aumentar a demanda turística e a permanência dos turistas na cidade. A participação é limitada, em razão das condições de cada organização e do dinamismo da cidade, que restringe o tempo de viagem dos turistas de negócios. O press trip "São Paulo Meu Destino" foi outro exemplo citado pelas direções de ambas as entidades.

A SPTuris e o SPCVB contribuem para promover o turismo da cidade na baixa temporada, por exemplo, por meio de apoio a eventos como Parada LGBT, Formula 1 e Formula Indy, que são conhecidos internacionalmente e atraem grande número de turistas. Eventos menores realizam-se durante todo o ano, aproveitando, principalmente, feriados prolongados, que estimulam tanto a participação dos morados locais quanto dos turistas. São eles: Visite São Paulo e Fique Mais um Dia, Turismetrô, Mapa das Sensações, Virada Cultural, Virada Esportiva, São Paulo Restaurant Week, entre outros.

A direção da SPturis informou que se realizam ações em cooperação com hotéis por meio de capacitações das equipes e divulgação no site da entidade. Para a SPTuris, um dos desafios dos serviços do turismo de lazer é que os city tours são realizados por empresas privadas, aumentando os custos para os turistas, que querem conhecer a cidade com guias. O fortalecimento da economia e do poder de consumo também são considerados desafios pela SPTuris, pois há encarecimento dos produtos e dos serviços turísticos, em razão do aumento da demanda em relação à oferta. Além disso, o trânsito, os problemas de acessibilidade, a violência e a poluição podem prejudicar a imagem da cidade.

As potencialidades da cultura, do lazer e do entretenimento, o aumento do poder aquisitivo da classe média, o fato de a cidade ser o maior hub aéreo do país e a verba pública destinada para divulgação e investimento em equipamentos de lazer são fatores competitivos destacados pela SPTuris. A qualidade dos serviços da hotelaria é avaliada como muito boa pela direção da entidade.

É importante observar que as visões das direções das duas entidades são diferentes em alguns aspectos, como por exemplo, a participação dos hotéis. A direção da SPTuris afirmou que eles participam de forma limitada, enquanto que a direção do SPCVB afirmou que participam ativamente. 
Para conhecer a visão dos atores da cultura, descrevem-se as respostas da direção da Secretaria Municipal de Cultura de São Paulo, para a qual o fluxo de turistas nos atrativos culturais tem sido satisfatório, enquanto o fluxo de paulistanos têm sido intenso. De acordo com a direção da Secretaria, as organizações do turismo e da hotelaria não atuam na promoção da cultura da cidade de São Paulo por não haver iniciativas de projetos criados culturais com essa finalidade. As organizações são convidadas a participar de parcerias para elaboração de projetos culturais, mas não participam. Logo, não há iniciativa, tanto por parte da Secretaria Municipal de Cultura quanto dos órgãos ligados ao turismo e à hotelaria.

De acordo com a direção da Secretaria, o principal obstáculo para atrair os turistas aos atrativos culturais é a falta de divulgação e de informação, e o órgão não elabora campanhas com a participação dos hotéis em sistema de cooperação. Não há participação de nenhuma rede hoteleira com investimentos em campanhas de promoção da cultura. Os segmentos que apresentam maior potencial para aumentar o fluxo de turistas na cidade de São Paulo são: espetáculos (shows e teatros); gastronomia; vida noturna (bares e danceterias); passeios (patrimônio histórico, museus, parques); exposições culturais; compras e esportes.

Para a direção da Secretaria, os atrativos culturais da cidade têm potencialidades para aumentar sua demanda de turistas, e as atividades são muito diversificadas, como: dança contemporânea, música popular brasileira, música erudita, cinema, exposições urbanas e workshops.

Com base nas respostas da direção da Secretaria Municipal de Cultura, verifica-se que a frequência dos turistas aos atrativos culturais, ainda que satisfatória, não é resultado de ações de promoção integrada pelos atores do cluster do turismo da cidade de São Paulo. Além disso, entende-se que não existem iniciativas, visando à participação das organizações da hotelaria e do turismo, para aumentar a demanda turística aos finais de semana, feriados e férias, por meio da criação de projetos de promoção da cultura, um dos referenciais da cidade.

A direção do FOHB afirma existirem períodos de sazonalidade na cidade e que a menor ocupação é, geralmente, entre os meses de dezembro e janeiro. Considera também os finais de semana como períodos de baixa ocupação. Para a direção do FOHB, existem parcerias entre os órgãos do turismo, da hotelaria e da cultura a fim de aumentar o fluxo e permanência dos turistas. Cita a "São Paulo Best Week" como exemplo de ações que apresentam essas finalidades e acrescenta que o papel da entidade nesse evento é estimular os hotéis a participarem.

Os segmentos com maior potencial para aumentar o fluxo e a permanência dos turistas na cidade, de acordo com a direção do FOHB, são os espetáculos (shows, teatros), compras e esportes. O turismo de lazer oferece opções para diversos segmentos de turistas. A criação e a divulgação de programações de lazer aos idosos e às famílias, entretanto, aumentariam o seu fluxo e a sua permanência. Para o FOHB, a principal oportunidade do turismo de lazer da cidade de São Paulo é a preparação e a divulgação da cidade para a Copa do Mundo de 2014. A qualidade geral dos serviços de hotelaria da cidade de São Paulo é avaliada pelo FOHB como muito boa, e os 
principais desafios do turismo de lazer são relacionados à segurança e ao trânsito, que afetam a imagem turística da cidade.

Quanto aos questionários aplicados aos gestores dos 25 hotéis, apenas quatro responderam que não existe baixa temporada do turismo na cidade de São Paulo. Os 21, que responderam existir baixa temporada, afirmaram que ela ocorre nos meses de dezembro a fevereiro, e oito deles incluíram o mês de julho. Confirmam-se, portanto, as informações da SPTuris. A taxa média de ocupação dos hotéis, de acordo com dez gestores, é pouco maior que $50 \%$ nos períodos citados como baixa temporada. Para sete gestores é cerca de $40 \%$, e para quatro é de $20 \%$ a $30 \%$. Quatro gestores não informaram a taxa.

A respeito do perfil dos clientes que se hospedam durante a semana nos hotéis em questão, quinze responderam que $60 \%$ e $80 \%$ são turistas a negócios ou a eventos profissionais, e dez responderam que os turistas desses segmentos são $80 \%$ a $100 \%$ do total do fluxo. Em relação ao turismo de lazer, seis gestores responderam que seus hotéis recebem de $40 \%$ a $60 \%$ de hóspedes desse segmento. Sete afirmaram que o segmento de turistas a lazer representa de $30 \%$ a $40 \%$ da ocupação, e os demais responderam que durante a semana seus hotéis recebem até $20 \%$ de turistas a lazer e entretenimento.

Seis gestores informaram que entre $80 \%$ e $100 \%$ dos hóspedes têm suas reservas feitas por terceiros (empresas). Oito informaram ser de $60 \%$ a $80 \%$, e seis de $40 \%$ a $60 \%$. Dois não informaram o percentual referente a reservas realizadas por meio de agências de viagens. Dois responderam que $20 \%$ a $40 \%$ das reservas são feitas por agências, quatro de $40 \%$ a $60 \%$, seis até $20 \%$, e dez responderam de $60 \%$ a $80 \%$.

Essa questão é importante, pois mostra que existe cooperação entre os atores da hotelaria com alguns segmentos de serviços do cluster de turismo, especialmente, com as agências de viagens.

Apenas quatro gestores responderam não desenvolverem estratégias para atrair turistas aos finais de semana, nas férias e em feriados. Dos 25 gestores, oito afirmaram não terem acordo com estabelecimento cultural, gastronômico, de compras ou de entretenimento da cidade. Doze gestores informaram oferecer diária cultural, que é uma tarifa diferenciada aos hóspedes que apresentarem algum documento (ingresso, voucher), comprovando sua participação em alguma atividade cultural (teatro, shows, etc.), no período de hospedagem.

Ainda que não se verifiquem ações de cooperação intensivas no contexto do cluster, da mesma forma que na questão anterior, verifica-se que existem articulações de diversos hotéis com o segmento de turismo de lazer cultural.

A fim de caracterizar os segmentos do cluster mais representativos em termos de potencialidades e de oportunidades de implementação de estratégias de inovação dos atrativos, os gestores responderam à questão de múltipla escolha relacionada às promoções dos segmentos para aumento do fluxo de turistas aos finais de semana, feriados e férias. 
Tabela 2 - Segmentos mais promovidos para atrair turistas

\begin{tabular}{|c|c|c|c|c|c|c|}
\hline Cultura & Gastronomia & Compras & Eventos & Negócios & Lazer & Esportes \\
\hline 10 & $\mathbf{8}$ & $\mathbf{8}$ & 4 & 4 & 4 & 2 \\
\hline
\end{tabular}

Dez hotéis realizam promoções ligadas à cultura; oito ligadas à gastronomia; oito a compras; quatro a eventos e negócios; quatro ligadas ao lazer e dois a esportes

Para a questão sobre quais segmentos os hóspedes mais solicitam informações, apresentam-se os seguintes resultados:

Tabela 3 - Segmentos Sobre os Quais os Hóspedes Mais Solicitam Informações

\begin{tabular}{|c|c|c|c|c|c|c|}
\hline Gastronomia & Compras & Cultura & Lazer & Eventos & Esportes & Negócios \\
\hline 18 & 16 & 12 & 12 & 4 & 2 & 2 \\
\hline
\end{tabular}

Dezesseis dos 25 gestores dos hotéis responderam que os órgãos ligados à promoção do turismo não executam ações suficientes para aumentar a demanda turística aos finais de semana, nas férias e em feriados.

Por fim, perguntou-se qual é a maior dificuldade para aumentar a demanda turística no período de baixa temporada, e a resposta é representada graficamente:

Tabela 5 - Dificuldades para aumentar a demanda

\begin{tabular}{|c|l|c|c|}
\hline $\begin{array}{l}\text { Falta de } \\
\text { Incentivo }\end{array}$ & $\begin{array}{l}\text { Preços } \\
\text { Elevados }\end{array}$ & Outros & $\begin{array}{l}\text { Falta de Opções } \\
\text { de Lazer }\end{array}$ \\
\hline 14 & $\mathbf{8}$ & $\mathbf{6}$ & $\mathbf{2}$ \\
\hline
\end{tabular}

Entre os gestores de hotéis que assinalaram a alternativa "outros", três afirmaram que a baixa demanda aos finais de semana é em razão do turismo de negócios, que dificulta o consumo do lazer. Três gestores mencionaram como um dos principais fatores que impedem o aumento da demanda aos finais de semana a falta de preparo de alguns profissionais que atuam no trade, pois grande parte de seus hóspedes são estrangeiros. Três gestores mecionaram os preços elevados, tanto dos hotéis quanto dos atrativos, e dois gestores mencionaram que a maior dificuldade é a falta de foco,

Pelas respostas, na visão dos gestores dos hotéis, não há suficiente cooperação entre as organizaçõe do cluster de turismo da cidade de São Paulo. Apesar de os hotéis realizarem promoções ligadas aos segmentos da gastronomia e da cultura, a afirmação da maioria dos gestores de que a taxa média de ocupação nos períodos de baixa temporada é de cerca de $50 \%$ e que faltam incentivos para aumentar a demanda, mostra que a governança do cluster ainda é limitada. Planejamento e gestão estratégicos abrangentes, com envolvimento mais amplo e mais direto das organizações públicas e privadas da cultura e do lazer, consolidariam o cluster de 
turismo da cidade de São Paulo como destino internacional, por meio dos diferenciais competitivos de seus diversos segmentos.

O cluster do turismo existe mais em razão da concentração geográfica das empresas e organizações do setor do que das parcerias que constituam a rede de cooperação, e várias organizações e atores ainda atuam individualmente no mercado do turismo. A gestão integrada e participativa, entretanto, tem potencial para avançar e se fortalecer, no sentido de consolidar-se a governança do cluster do turismo da cidade de São Paulo.

\section{CONSIDERAÇÕES FINAIS}

Nas características do cluster de turismo da cidade de São Paulo, destacam-se informações de pesquisas do São Paulo Convention \& Visitors Bureau e do Observatório de Turismo da SPTuris, que mostram que $77 \%$ dos turistas são de negócios e eventos, e $70 \%$ a $80 \%$ de suas chegadas e saídas acontecem de segundas-feiras a sextas-feiras. De 2005 a 2011, a taxa média de ocupação da hotelaria foi de $67 \%$ a $70 \%$, nos meses de março a novembro, e de $53 \%$ a $58 \%$ nos meses de dezembro, janeiro e fevereiro. Nos últimos anos, durante a semana, a taxa média de ocupação tem sido de $82 \%$, em razão do turismo de negócios, e de $58 \%$ nos finais de semana, o que representa diferença de $40 \%$ entre entre as duas taxas médias.

Em razão da configuração econômica - indústria, comércio e serviços - da cidade de São Paulo, é coerente que as organizações concentrem suas estratégias de marketing no segmento de turismo de negócios, mas podem também contemplar essa demanda como oportunidade para direcioná-la aos atrativos de cultura e de lazer. As estratégias justificam-se em razão de o fluxo de turistas dos segmentos de cultura e lazer, aos finais de semana, ter aumentado de 30\% para 60\% nos últimos 11 anos e poderá até igualar-se futuramente ao fluxo e à ocupação hoteleira do segmento de turistas de negócios.

A SPTuris e o SPCVB realizam diversos projetos para aumentar a demanda turística na baixa temporada, como Visite São Paulo e Fique Mais Um Dia. Esses projetos poderiam ter mais participação das empresas privadas de turismo e de lazer para retornos e benefícios abrangentes, por meio da maior divulgação dos museus, shows, teatros, restaurantes, centros culturais, projetos sociais, parques. Os turistas que já frequentam a cidade a negócios podem desfrutar mais desses atrativos, bem como mais turistas podem ser atraídos em razão desses segmentos.

É provável que muitos turistas que visitam a cidade não se interessem em conhecê-la profundamente por não terem clareza da variedade de seus atrativos e dos projetos desenvolvidos pela São Paulo Turismo (SPTuris) e pelo São Paulo Convention \& Visitors Bureau (SPCVB).

Enfatiza-se que é importante que os atores do cluster implementem mais parcerias para o desenvolvimento do turismo da maior cidade da América Latina. Com maior cooperação entre eles, os custos com investimentos seriam menores para todas as organizações. Em contrapartida, haveria mais retornos da soma do investimento coletivo, dificilmente alcançado pela ação isolada ou individual. 
Para articulação e consolidação do cluster do turismo na cidade de São Paulo, é necessária melhor definição da governança, por meio da comunicação e da interação entre os atores, do fortalecimento dos projetos e criação de novos projetos para inovação dos atrativos, produtos e serviços turísticos.

O São Paulo Convention \& Visitors Bureau (SPCVB) seria a organização com maiores condições de governança do cluster de turismo da cidade, em razão do seu número de associados, de sua dimensão e abrangência. Mas é preciso maior sintonia, comunicação e intercâmbio entre o SPCVB, a São Paulo Turismo (SPTuris), a Secretaria Municipal da Cultura, o Fórum de Operadores Hoteleiros do Brasil (FOHB) e as demais organizações dos diversos segmentos (hotelaria, gastronomia, lazer, esportes, comércio, agências).

De acordo com as respostas ao questionário de 21 dos 25 gestores hoteleiros, o turismo da cidade de São Paulo apresenta características de sazonalidade. Para vários deles, a taxa média de ocupação é de, no máximo, $40 \%$ nos períodos de baixa temporada (dezembro, janeiro e fevereiro), percentual menor do que o mostrado por outras pesquisas como da SPTuris, que é de $53 \%$. Também para a direção do Fórum de Operadores Hoteleiros do Brasil (FOHB), existem períodos de sazonalidade.

Os gestores mostram interesse e dedicação em aumentar o fluxo de turistas a lazer aos finais de semana, nos feriados e nas férias, pois já implementam algumas ações, como tarifas promocionais incluindo atrativos culturais. A maioria dos 25 respondentes afirmou manter acordos com empresas de segmentos gastronômicos, culturais e de compras. Infere-se que eles esperam que o poder público empreenda mais iniciativas, pois a dificuldade mais destacada é a falta de incentivos. Praticamente todos os gestores destacam a cultura, a gastronomia e as compras como segmentos de significativas potencialidades para aumentar o tempo de permanência e para atrair mais fluxos de turistas à cidade de São Paulo, especialmente aos finais de semana, nos feriados e nos períodos de férias. Uma das propostas seria enfatizar a segmentação de mercado, adequando as estratégias de marketing aos diversos perfis de demandas turísticas, de acordo com a visão do Fórum de Operadores Hoteleiros do Brasil (FOHB).

A hotelaria é uma das quatro atividades essenciais do turismo, juntamente com transportes, atrativos e serviços de apoio, e representa diferencial competitivo importante da cidade em relação a outros destinos nacionais e internacionais. A concentração geográfica não é, entretanto, determinante para a eficiência coletiva. É preciso fortalecer a governança, por meio das relações entre os gestores e da dinamização da rede de cooperação.

O desenvolvimento sustentável por meio da constante inovação e da melhoria da qualidade da infraestrutura, dos produtos, dos serviços e dos atrativos é o principal desafio dos gestores públicos e privados do cluster turístico paulistano. Nesse sentido, é importante a atuação e a participação das instituições de ensino e pesquisa. O trabalho do Observatório de Turismo, da SPTuris, é relevante, e poderia haver mais espaços de intercâmbios para o desenvolvimento do turismo e do lazer também no campo acadêmico.

\section{REFERÊNCIAS}

Albagli, Sarita e Maciel, Maria Lúcia (2003). Capital social e desenvolvimento local. In: Lastres, M. H. et al. Pequena empresa: cooperação e desenvolvimento local. Rio de Janeiro: Relume Dumará. 
Amato Neto, João (2008). Redes de cooperação produtiva e clusters regionais: oportunidades para as pequenas e médias empresas. São Paulo: Atlas.

Ansarah, Marília (2005). Turismo e segmentação de mercados: novos segmentos. In: Trigo, Luiz G. Análises regionais e globais do turismo brasileiro. São Paulo, Roca, p. 285-299.

Beni, Mário Carlos (2001). A Serra Gaúcha e seu potencial para conversão em cluster turístico. In: Barretto, Margarita; Rejowski, Mirian (Org.). Turismo: interfaces, desafios e incertezas. Caxias do Sul (RS): Educs.

Beni, Mário Carlos (2011). Globalização do turismo: megatendências do setor e realidade brasileira. São Paulo, Aleph.

Brito, J. E Albagli, S. (2003). Glossário de arranjos e sistemas produtivos e inovativos locais. Rede de Pesquisa em Sistemas Produtivos e Inovativos Locais. Rio de Janeiro: RedeSist.

Brasil. Ministério do Turismo (2008). Turismo de negócios \& eventos: orientações básicas. Brasília.

Cassiolato, José e.; Szapiro, Marina (2003). Uma caracterização de arranjos produtivos locais de micro e pequenas empresas. In: Lastres, Helena M. M.; Cassiolato, José E.; Maciel, Maria L. (Org.). Pequena Empresa: cooperação e desenvolvimento local. Rio de Janeiro: Relume-Dumará.

Cunha, Sieglinde K; CUNHA, João C. (2006). Cluster de turismo: abordagem teórica e avaliação. Revista de Desenvolvimento Econômico. Ano VIII, n.13, janeiro.

IBGE -Instituto Brasileiro De Geografia E Estatística (2012). Disponível em <www.ibge.gov.br>. Acesso em 30 Ago.

Lohmann, Guilherme; Panosso Netto, Alexandre (2008). Teoria do turismo: conceitos, modelos e sistemas. São Paulo: Aleph.

Porter, Michael (1998). Clusters and new economics of competition. Novembro/Dezembro EUA: Harvard Business Review.

Porter, Michael. E. (1999). Competição: estratégias competitivas essenciais. Rio de Janeiro: Campus.

São Paulo. Prefeitura da Cidade de São Paulo (2011). Disponível em: <http://www.prefeitura.sp.gov.br/portal/a cidade/historia/index.php?p=4673>. Acesso em: 19 ago.

Schumpeter. A teoria do desenvolvimento econômico (1985). São Paulo: Nova Cultural (Os economistas).

Silva, Jorge A. S. (2004). Turismo, crescimento e desenvolvimento: uma análise urbano-regional baseada em cluster. Tese de Doutorado em Ciências da Comunicação; Área de Concentração: Turismo. Escola de Comunicações e Artes, Universidade de São Paulo. São Paulo.

SPCVB - São Paulo Convention \& Visitors Bureau (2011). Dados da cidade. Disponível em:

$<$ www.visitesaopaulo.com/dados-da-cidade.asp $>$. Acesso em: 07 jul.

SPTuris - São Paulo Turismo (2011). O melhor destino para os seus eventos e negócios. Disponível em: $<$ www.cidadedesaopaulo.com/sp/br/negocioseeventos $>$. Acesso em: 07 jul.

Observatório do Turismo da Cidade de São Paulo (2011). Observatório de tendências: perfil dos hóspedes em meios de hospedagem paulistanos. Disponível em: <www.cidadedesaopaulo.com/sp/br/>. Acesso em: $07 \mathrm{set}$. 
Santos, Maria Helena de Castro(1997). Governabilidade, governança e democracia: criação da capacidade governativa e relações executivo-legislativo no Brasil pós-constituinte. In: Dados - Revista de Ciências Sociais. Rio de Janeiro, volume 40, N. 3, p. 335-376.

Thomazi, Silvia M. (2006). Cluster de turismo: introdução ao estudo de arranjo produtivo local. São Paulo: Aleph.

Tomazzoni, Edegar L. (2009). Turismo e desenvolvimento regional: dimensões, elementos e indicadores. Caxias do Sul (RS): Educs.

Artigo recebido em: 25/07/2012. Artigo aprovado em: 01/11/2014 